\title{
MODELING AND ANALYSIS OF ABSORBING BOUNDARY CONDITION IN ANTENNA DESIGN
}

\author{
Umut Ozkaya $^{1}$, Levent Seyfi²
}

\begin{abstract}
In this study, the absorbing boundary condition is modelled and analyzed by particle swarm optimization for antenna designs. Two pieces of circular and rectangular microstrip patch antennas are designed for results by means of High Frequency Structure Simulator (HFSS) simulation program. These antennas are implemented by printed circuit board technologies. The results of measurements and simulation performed for the antenna determined the optimal absorbing boundary distance. . In order to be closer with simulation and measurement results, data set is generated by varying in absorbing boundary size. Average square error between simulation and measurement data is necessary to be optimized as an objective function. For this reason, optimization algorithm based on swarm intelligence is preferred to be minimized the error function. Thanks to the results of measurements and simulation performed with the antenna, optimal absorbing boundary distance is determined by Particle Swarm Optimization.
\end{abstract}

UDC Classification: 621.3 DOI: http://dx.doi.org/10.12955/cbup.v4.861

Keywords: Microstrip Patch Antenna, Absorbing Boundary Condition, HFSS, Particle Swarm Optimization

\section{Introduction}

An antenna can be behaved as a transceiver for sending or receiving radio waves (Kim J. I. and et al, 2007). Since the beginning of the 1990s, ongoing developments in the radio frequency (RF) technology has led to the proliferation of communication tools in different sectors. With the increasing use of wireless communication systems by individuals or communities, microstrip patch antennas began to come more to the fore.

In 1953, radiation of the microstrip was first detected by Deschamps (1953) and patented by Gutto and Baissinot (1955). Following this idea, there was no improvement in microstrip for many years. With significant increase in studies, microstrip antennas were made for placement on the surface of missiles and spacecraft in the 1970s (Gutton H. and et al, 1955).

The microstrip patch antenna has certain advantages, such as small size, low profile, compatibility planar, and non-planar surface suitable for modern printed circuit board as well as low cost and simple to produce. It is preferred for satellite systems, global positioning system, wireless communications systems, and radar systems owing to these advantages (Gao L. L and et al, 2010). However, deficiencies in microstrip antennas include the narrow bandwidth, low efficiency, and gain leading to restrictions in the application platform (Aslam, A. and et al, 2010).

A major advance in the analysis software occurred with the development of technology in the design and production. In recent years, High Frequency Structure Simulator (HFSS), Computer Simulation Technology (CST Microwave Studio), Maxwell, and Zeland IE3D programs have been used for antenna designs. In this study, the HFSS program is preferred as the analysis software.

\section{Microstrip Antenna}

The microstrip antenna is made up of a conductive radiating patch disposed on dielectric substrate and ground plane at the bottom. It is produced by printed circuit technique as shown in Figure 1. Radiating patch is selected from low-loss metallic material such as copper. A microstrip antenna includes patch sizes as width (W) and length (L), substrate thickness (h) and dielectric constant $\left(\varepsilon_{r}\right)$. These are the main factors that affect antenna performance.

Generally, patch thickness should be selected from the range: $0.0-0.1 \mathrm{~mm}$. Ground plane consists of conductive materials of a similar patch. On the other hand, the dielectric substrate is proposed from materials with different dielectric constant and tangent loss, for instance, ceramic, Teflon, air, and epoxy. Thickness of dielectric material (h) can be selected in the range: $0.003-0.050 \lambda$. Dielectric

\footnotetext{
${ }^{1}$ Umut Ozkaya, Selcuk University, Faculty of Engineering, Konya/Turkey, uozkaya@selcuk.edu.tr

${ }^{2}$ Levent, Seyfi, Selcuk University, Faculty of Engineering, Konya/Turkey, leventseyfi@selcuk.edu.tr
} 
constant $\left(\mathcal{E}_{r}\right)$ can also be used in the range: $2.2-12.0$, to obtain more suitable antenna dimensions. Low dielectric constants and high thickness of base materials are desirable for antenna performance (Balanis C. A., 2005). Moreover, these characteristics can increase the bandwidth of the antenna. However, an increase in thickness of dielectric material leads to distortion in radiation patterns and low gains (Pozar D. M. and et al, 1995).

Figure 1: Microstrip antenna geometry

Microstrip antennas are formed by placing the desired patch geometry on the dielectric base. Either the planar or non-planar patch geometries are often used. The well-known patch includes rectangular, square, triangular, and circular geometries. In addition, it is shaped in " $\mathrm{H}$ " and " $\mathrm{E}$ " forms as different geometric structures. Some microstrip patch antenna geometry in the literature is shown in Figure 2.

\begin{tabular}{|l|}
\hline Figure 2: Well-known Patch Geometries \\
\hline Source: Balanis (2005) \\
\hline
\end{tabular}

Researchers have generally focused overall on rectangular and circular microstrip antennas due to the simplicity of the geometry and the analysis involved. Furthermore, these antennas are easily designed at the desired operating frequency, bandwidth, and gain by means of empirical formula. Slots and notches with changes in patch geometry increase the bandwidth of the antenna and some slot and notch models are shown in Figure 3.

A transmission line model is utilized for the microstrip patch antenna design. Operating frequency $\left(\mathrm{f}_{\mathrm{o}}\right)$, rectangular patch dimensions $(\mathrm{W}, \mathrm{L})$, the thickness of dielectric substrate $(\mathrm{h})$, and patch $(\mathrm{t})$ are calculated by the following formula:

Patch width

$$
\mathrm{W}=\frac{\mathrm{c}}{2 \mathrm{f}_{o}}\left(\frac{2}{\varepsilon_{\mathbf{r}}+1}\right)^{1 / 2}
$$

$\mathrm{W} / \mathrm{h}>1$ 


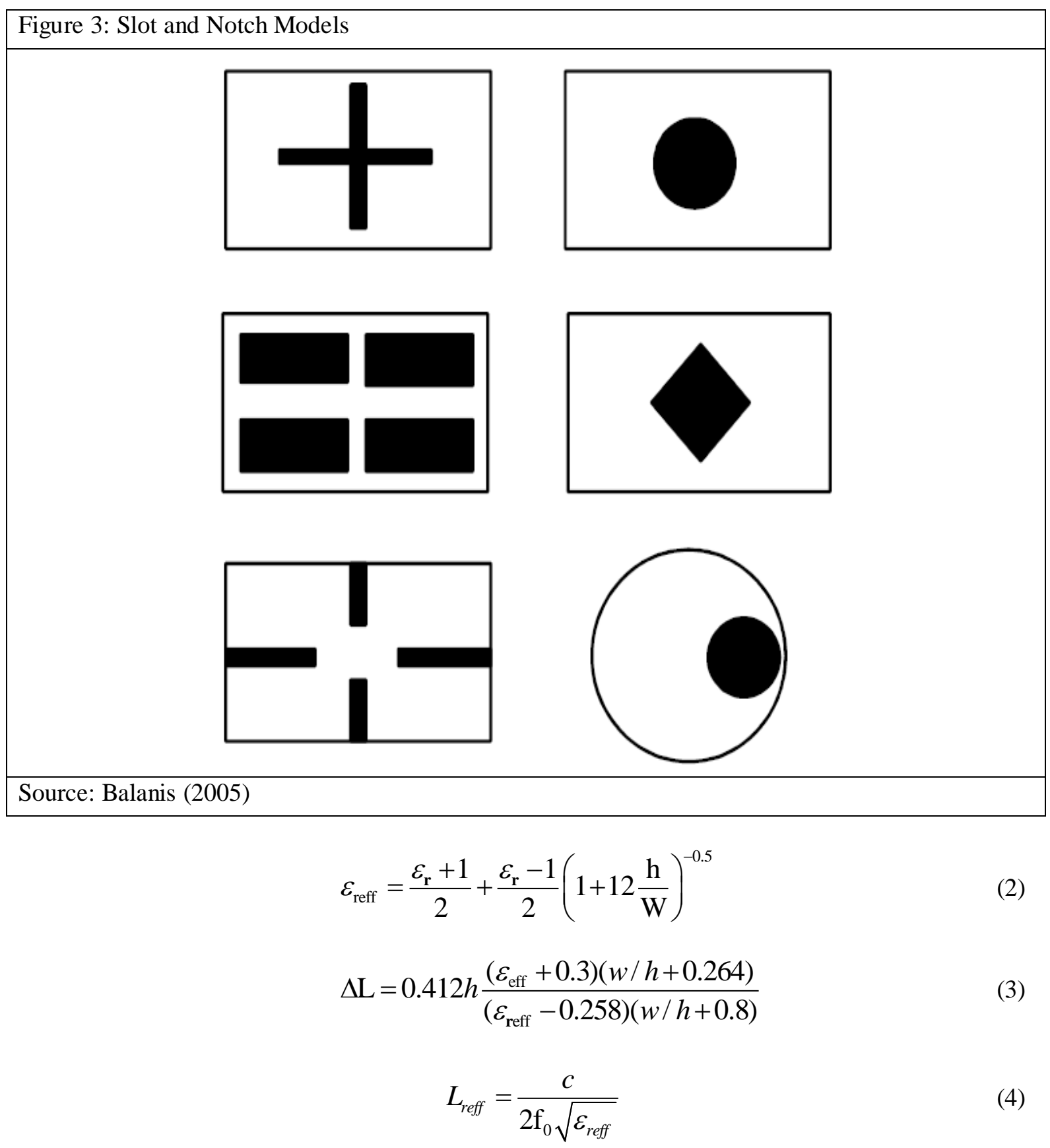

Patch Length

$$
\mathrm{L}=\mathrm{L}_{r e f f}-2 \Delta \mathrm{L}
$$

With operating frequency $\left(f_{o}\right)$ and dielectric thickness (h), the radius of the circular patch (a) can be determined mathematically:

$$
\begin{gathered}
\mathrm{F}=\frac{8.791 x 10^{9}}{f_{o}\left(\varepsilon_{r}\right)^{1 / 2}} \\
\mathrm{a}=\frac{F}{1+\frac{2 h}{\pi \varepsilon_{r} \mathrm{~F}}\left[\operatorname{In}\left(\frac{\pi F}{2 h}\right)+1.772\right]}
\end{gathered}
$$


The aim of feed techniques in the microstrip antenna is to provide the best impedance matching as possible. Impedance matching is defined as a large amount of power delivered from the feed line to the metallic patch. However, feed technique is considered more important for a microstrip antenna.

Probe feed is a technique where a probe passing through the dielectric layer is soldered onto a metallic patch. Probes may be any conductor or coaxial cable, but, the probe must be placed in a suitable position in order to match impedance.

Figure 4: Top and front view of microstrip antenna with feed probe

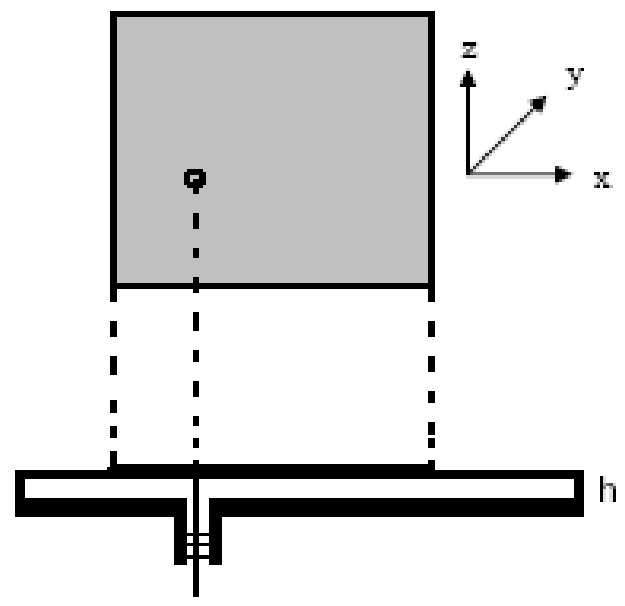

Source: Balanis (2005)

The electric field $\left(\mathrm{E}_{\mathrm{z}}\right)$ component is the supply current $\left(\mathrm{J}_{\mathrm{Z}}\right)$ that contributes impulses to the patch. Hence, feed position is located in two-dimensional patch space as shown in Figure 4.

In the microstrip line feed technique, power is transferred by a smaller conductive path to the patch (Figure 5). The advantages of line feed purportedly are that strip line comprises the same material as the patch and this establishes a planar surface. Thus, reduction in surface ripple is observed. In addition, integration of the strip line to the patch antenna is easier (Garg R. and et al, 2001).

This feed technique has many limitations, though easy to design and produce. The losses caused by external radiation has greater effect at higher frequencies where an air gap exists between the patch and the feed. A rematch of the impedance may be necessary because of changes in the line impedance.

\begin{tabular}{|l|}
\hline Figure 5: Microstrip line feed \\
\hline Source: Garg et al. (2001) \\
\hline
\end{tabular}

Feed line is separated from a metallic patch by a ground plane in Aperture Coupled Feed (ACF) technique (Figure 6). Energy is initially transferred to the groove and then, it is conducted to the dielectric substrate by the ground plane. The groove should be positioned at the highest level of 
magnetic field on the patch plane (Carver K. R. and et al, 1981). Thanks to the ACF, unexpected losses can be eliminated and also bandwidth may be increased by the right groove position.

\begin{tabular}{|l|l|}
\hline Figure 6: Aperture coupled feed \\
\hline Source: Carver and Mink (1981)
\end{tabular}

\section{Modeling and PSO Analysis of Absorbing Boundary Condition}

An absorbing boundary condition significantly affects the microstrip patch antenna parameters. It is modelled in air by design software to present a close resemblance to reality. Simulation and measurement results are intended to be similar for antenna design. Figure 7 shows how absorbing boundary conditions modeled in the simulation software varies in accordance with wavelength. In the literature, absorbing boundary conditions is recommended for selection at as least a quarter-wave $(\lambda / 4)$ distance.

\begin{tabular}{|l|l|}
\hline Figure 7: Absorbing boundary condition \\
\hline $\begin{array}{l}\text { Absorbing } \\
\text { Boundary } \\
\text { Condition }\end{array}$ \\
\hline Source: Author
\end{tabular}

Rectangular and circular patch microstrip antennas are designed in HFSS simulation software for the purpose of analyzing the absorbing boundary condition shown in the Figure 7. Antennas are feed by a coaxial probe. The Flame Retardant 4 (FR4) and Duroid dielectric materials are commonly preferred for production of microstrip antenna. Operating frequency and return losses are ordinarily between $1.5-3.0 \mathrm{GHz}$ and $10-30 \mathrm{~dB}$. 


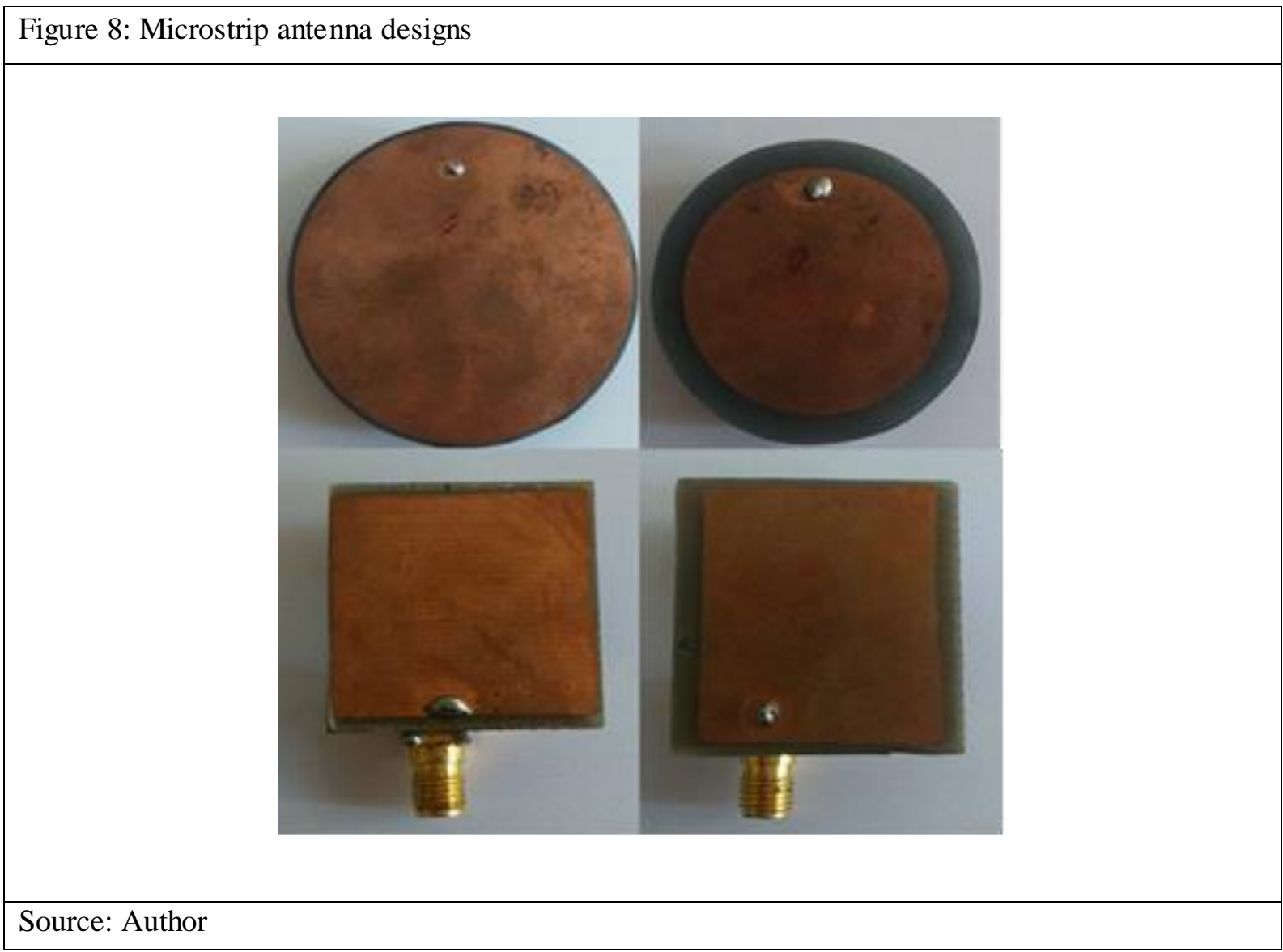

Particle swarm optimization (PSO), which is inspired from the behavior of animals swarming, was developed by Kennedy and Eberhart (1995). These types of algorithms are based on swarm intelligence. Swarm behaviors related to anxiety about food security, help achieve their aims. Social information networks between individuals is important for PSO. Particles try to update their position by means of previous experience in PSO as shown in the flow diagram (Figure 10). Generally, individuals in the swarm have better positions than in the past and also they continue swarming until the best position is reached (Wilke, 2005).

The algorithm basically consists of the following steps:

1. Initial swarm is generated with random position and velocity.

2. Fitness values of all the particles are computed.

3. The local best position (pbest) is found for each particle. The number of the best local position in the swarm is equal to the number of particles.

4. The best in local best positions is selected and assigned as global best position (gbest) in the current generation.

5. The following formulas are used to update position and velocity:

$$
\begin{gathered}
\mathrm{V}_{i d}(\mathrm{t}+1)=\mathrm{W} \times \mathrm{V}_{i d}(\mathrm{t})+\mathrm{c}_{1} \times \operatorname{rand}_{1} \times\left(\mathrm{P}_{i d}-\mathrm{X}_{i d}(t)\right)+\mathrm{c}_{2} \times \operatorname{rand}_{2} \times\left(\mathrm{P}_{g d}-\mathrm{X}_{i d}(t)\right) \\
X_{i d}(t+1)=X_{i d}(t)+V_{i d}(t)
\end{gathered}
$$

where $X_{\text {id }}(t)$ represents current position of particles; current velocity of particle is shown as $V_{\text {id }}$; $\operatorname{rand}_{1}$ and rand ${ }_{2}$ are random numbers; $\mathrm{W}$ is the inertia value, depending on iteration number; and $c_{1}$ and $c_{2}$ are scale factors for optimization algorithm.

In the algorithm, the previous steps continue in a loop until the stop criteria. 


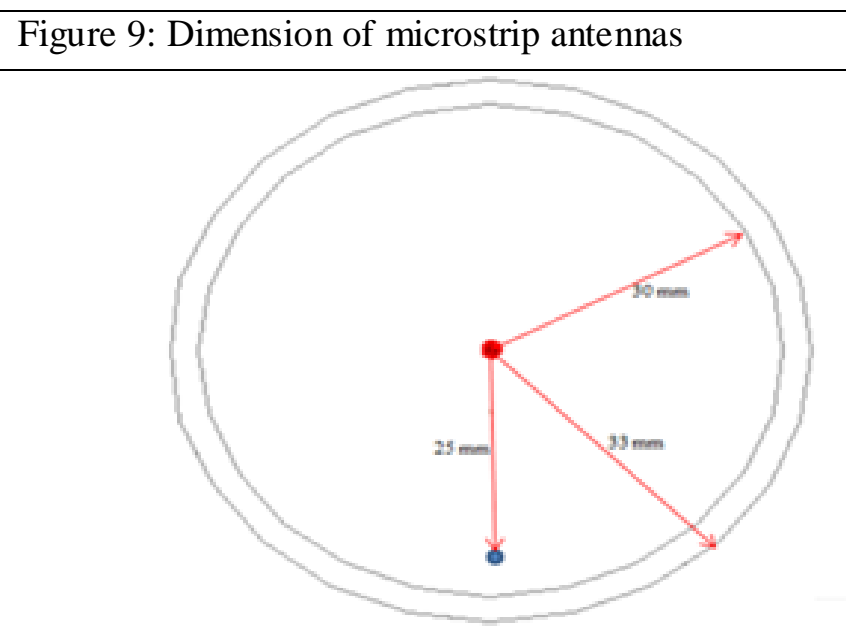

(a)

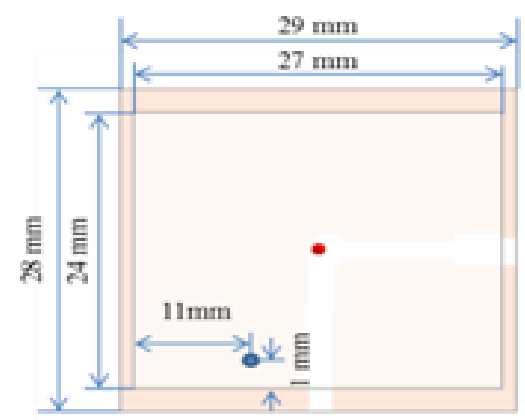

(c)

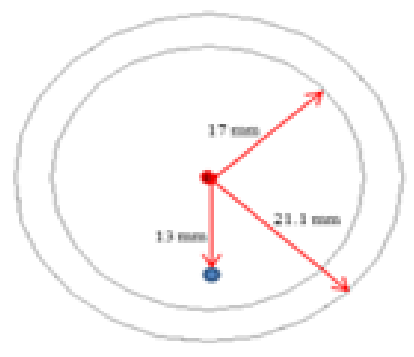

(b)

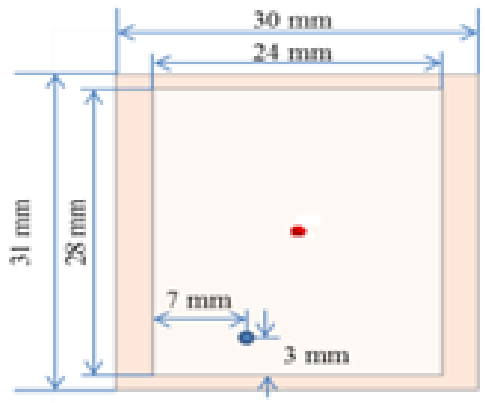

(d)

Source: Author

Figure 10: Flow chart for Particle Swarm Optimization

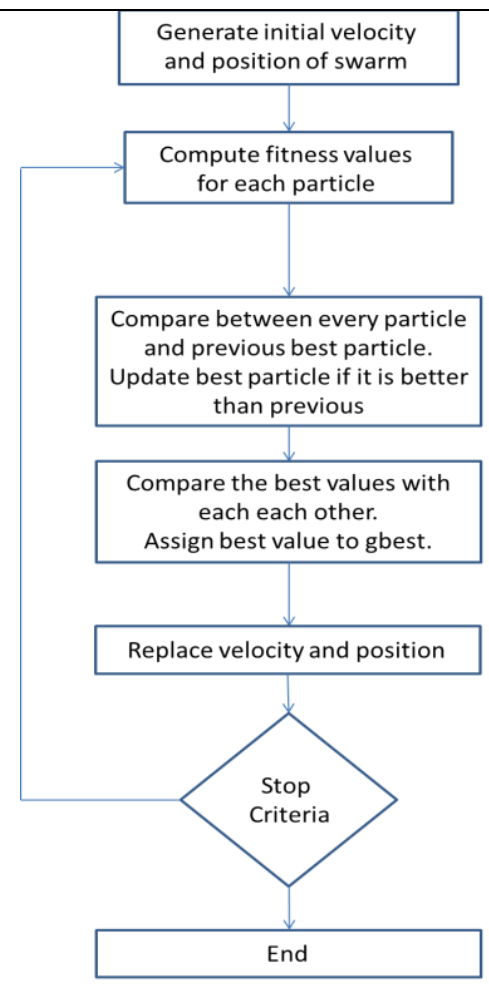

Source: Author 


\section{Results}

In this study, a total of four microstrip patch antennas were designed using the HFSS simulation software. The distance between absorbing boundary and antenna were tuned as $\lambda / 20, \lambda / 10, \lambda / 8, \lambda / 4$, $\lambda / 2,3 \lambda / 4, \lambda, 5 \lambda / 4$, and $3 \lambda / 2$. The effect of distance on antenna parameters were observed. Manufactured using printed circuit technology with circular and rectangular microstrip patch, antennas' measurements were performed by ROHDE-SCHWARZ network analyzer. In order to resolve differences between the simulation and measurement results, obtained data were assessed by PSO. For antennas in $1.5-3.0 \mathrm{GHz}$, optimum boundary distance was determined as $0.843 \lambda$.

\section{Conclusion}

This paper presents an Artificial Neural Network by modifying Particle Swarm Optimization algorithm in order to determine absorbing boundary condition for antenna design. Reference return losses and operating frequency is assigned as inputs in this ANN model; on the other hand, length of absorbing boundary is an unique output of modified ANN. The modified optimizer success in converging the optimal value with a small error. The proposed optimizer provides closer simulation and measurement results for antenna design.

\section{References}

Aslam, A., \& Bhatti, F. A. (2010). Improved Design of Linear Microstrip Patch Antenna Array. In Proc, 9th Int. Symp. on Antennas Propagation and EM Theory, pp. 302-306.

Balanis, C. A. (2005). Antenna Theory, Third Edition ed. Arizona State University: John Wiley \& Sons, Inc.

Carver, K. R., \& Mink, J. W. (1981). Microstrip Antenna Technology. IEEE Trans. Antennas and Propagation, Vol. AP-29, no. 1, pp. 2-24.

Deschamps, G. A. (1953). Microstrip Microwave Antennas. Presented at the Third USAF Symposium on Antennas.

Gao, S. C., Li, L. W., Leong, M. S., \& Yeo, T. S. (2010). Analysis of an H-shaped Patch Antenna by Using the FDTD Method. Prog. In Electromagnetics Research, National University of Singapore, pp.165-187.

Garg, R., Bhartia, P., Bahl, I., \& Ittipiboon, A. (2001). Microstrip Antenna Design Handbook. Artech House Antennas and Propagation Library, 1-2.

Gutton, H., \& Baissinot, G. (1955). Flat Aerial for Ultra High Frequencies. French Patent No. 703113.

Kennedy, J., \& Eberhart, R. C. (1995). Particle Swarm Optimization. Proc. of the IEEE Int. Conference on Neural Networks, 4, 1942-1948.

Kim, J. I., \& Jee, Y. C., (2007). Design of Ultrawideband Coplanar Waveguide-Fed LI-Shape Planar Monopole Antennas. Antennas and Wireless Propagation Letters IEEE, 6:383-387.

Pozar, D. M., \& Schaubert, D. H. (1995) Microstrip antennas. IEEE Press, New York.

Wilke, D. N. (2005) Analysis of the particle swarm optimization algorithm, Master Thesis, Mechanical and Aeronautical Engineering, University of Pretoria. 